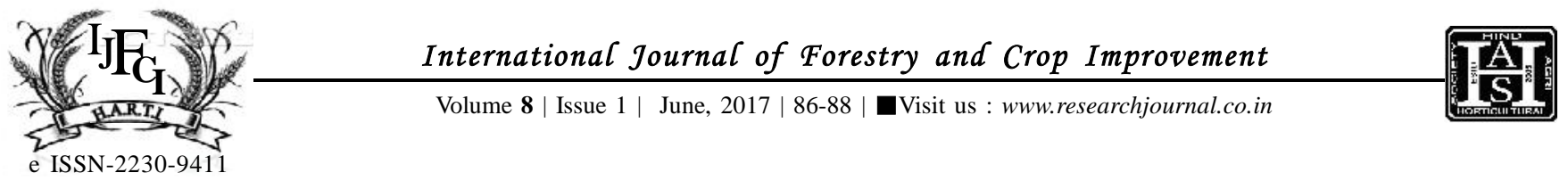

\title{
Physical and mechanical properties of particle board made from lops and tops of Populus deltoides and Broussonetia papyifera
}

\author{
ANIL KUMARAND KAPIL SIHAG
}

\begin{abstract}
The present study was carried out with an objective to evaluate the density, moisture content, water absorption, general swelling, surface absorption, modulus of rupture, internal bonding and screw withdrawal strength of experimental Particle Board prepared from admixture (50:50) of Populus deltoides and Broussonetia papyifera. The Particle Boards were made with 8 per cent, 10 per cent and 12 per cent Phenol Formaldehyde resin and hot pressed at $21 \mathrm{~kg} / \mathrm{cm}^{2}$ for 12 minute. The physical and mechanical properties of resulted Particle Board meet the requirement of Indian Standard specification IS: 3087 (1985). The swelling of board is slightly higher than the require Indian Standard specification (3087) which can be controlled by suitable treatment.
\end{abstract}

KEY WORDS : Populus deltoides, Broussonetia papyifera, Particleboard, Phenol formaldehyde, Specific pressure

HOW TO CITE THIS ARTICLE : Kumar, Anil and Sihag, Kapil (2017). Physical and mechanical properties of particle board made from lops and tops of Populus deltoides and Broussonetia papyifera. Internat. J. Forestry \& Crop Improv., 8 (1) : 86-88, DOI: 10.15740/HAS/IJFCI/8.1/ 86-88.

Article Chronical : Received : 22.04.2017; Accepted : 26.05.2017 